\title{
Exhalant jet speed of single-osculum explants of the demosponge Halichondria panicea and basic properties of the sponge-pump
}

\author{
Goldstein, Josephine; Riisgård, Hans Ulrik; Larsen, Poul S.
}

Published in:

Journal of Experimental Marine Biology and Ecology

Link to article, DOI:

10.1016/j.jembe.2018.11.009

Publication date:

2019

Document Version

Peer reviewed version

Link back to DTU Orbit

Citation (APA):

Goldstein, J., Riisgård, H. U., \& Larsen, P. S. (2019). Exhalant jet speed of single-osculum explants of the demosponge Halichondria panicea and basic properties of the sponge-pump. Journal of Experimental Marine Biology and Ecology, 511, 82-90. https://doi.org/10.1016/j.jembe.2018.11.009

\section{General rights}

Copyright and moral rights for the publications made accessible in the public portal are retained by the authors and/or other copyright owners and it is a condition of accessing publications that users recognise and abide by the legal requirements associated with these rights.

- Users may download and print one copy of any publication from the public portal for the purpose of private study or research.

- You may not further distribute the material or use it for any profit-making activity or commercial gain

- You may freely distribute the URL identifying the publication in the public portal 


\title{
Exhalant jet speed of single-osculum explants of the demosponge Halichondria panicea and basic properties of the sponge-pump
}

\author{
Josephine Goldstein ${ }^{1, *}$, Hans Ulrik Riisgård ${ }^{1} \&$ Poul S. Larsen ${ }^{2}$ \\ ${ }^{1}$ Marine Biological Research Centre, University of Southern Denmark, Hindsholmvej 11, DK-5300 Kerteminde, \\ Denmark \\ ${ }^{2}$ DTU Mechanical Engineering, Fluid Mechanics, Technical University of Denmark, Building 403, DK-2800 Kgs. \\ Lyngby, Denmark \\ ${ }^{*}$ Corresponding author
}

\begin{abstract}
Sponges are modular organisms in which each aquiferous module draws water
\end{abstract} through a canal system by means of pumping units (choanocyte chambers, $C C$ ), and the filtered water leaves the module as an exhalant jet through a single opening (osculum). A constant density of $C C$ s in sponges would imply that the filtration rate must be proportional to the sponge volume, but it is less obvious how the osculum cross-sectional area (OSA) scales to sponge volume. Here, we present data obtained on single-osculum sponge explants (i.e. single aquiferous modules) of the demosponge Halichondria panicea to get a better understanding of the basic properties of the sponge-pump. In the experimental study of 27 explants (volume $V_{\mathrm{s}}=$ 14 to $\left.1977 \mathrm{~mm}^{3}\right)$ osculum cross sectional area $(O S A)$, exhalant jet speed $\left(U_{0}\right)$ and filtration rate $\left(F=O S A \times U_{0}\right)$ were measured. The observed scaling with size $\left(O S A \sim V_{\mathrm{s}}^{0.66} ; U_{0} \sim O S A^{0.45} ; F \sim\right.$ $O S A^{1.45}$ ) was found to be close to that inferred from the hypothesis of volume based $C C$ density. Thus, the volume-specific filtration rate (= pumping rate) could be approximated as $F\left(\mathrm{ml} \mathrm{min}^{-1}\right)$ $\approx 2.3 V_{\mathrm{s}}\left(\mathrm{cm}^{3}\right)$ which is of the same order of magnitude as that of the demosponge Haliclona urceolus, $F\left(\mathrm{ml} \mathrm{min}^{-1}\right) \approx 3.5 V_{\mathrm{s}}\left(\mathrm{cm}^{3}\right)$. This suggests that for the two sponge species $C C$ s are very likely of similar size, with similar individual pumping rate, and of similar uniform distribution over the sponge volume. By comparing the observed increase of $U_{0}$ with increasing $O S A$ to literature data on other leuconoid sponge species this revealed a power function with an identical exponent 0.45 and maximum values of $U_{0}=6$ to $8 \mathrm{~cm} \mathrm{~s}^{-1}$. This indicates that $U_{0}$ of a singleosculum explant, or $U_{0}$ of an individual osculum in a multi-oscula sponge approaches an upper limit as the sponge grows, implying that a module of a multi-oscula sponge may increase only to a certain size. Time-lapse video-microscope recordings of sponge explants showed temporal variation in $O S A$ during spontaneous contractions. Exposure to a neurotransmitter (GABA) as well as overloading with ink particles triggered contractions that correlated with both decreasing $O S A$ and $U_{0}$ that eventually became zero. Video-microscope recordings revealed that it was contraction of the endopinacoderm lining the excurrent canals that effectively restricted or stopped the water flow. 
Key words: filtration rate, osculum area, scaling, contraction, aquiferous module, videomicroscope recording

\subsection{Introduction}

Filter-feeding benthic invertebrates need to process large amounts of water, and to prevent once filtered water from reentering the animals they discharge this water as an exhalant jet through a constricted exhalant opening (Vogel, 1994). Another function of exhalant jets may be to mix the near-bottom water because such "biomixing" provides an increased downward flux of suspended food particles (Riisgård and Larsen, 2017). Both functions depend on jet speed and distance of penetration of the jet into the surrounding water. Knowledge about jet speeds and allometry may further deepen our understanding of the principles of biological filter-pumps. For example, by scaling it can be suggested that the velocity of the exhalant jet in mussels, Mytilus edulis, is constant, independent of mussel size, as also found experimentally, $U_{0} \approx 8 \mathrm{~cm} \mathrm{~s}^{-1}$ for mussels of shell length $L=16$ to $83 \mathrm{~mm}$ (Riisgård et al., 2011). The reasoning is this. For known filtration rate $(F$; also termed volumetric flow or pumping rate) and cross-sectional area $(A)$ of the exhalant opening (assumed to scale as $A \sim L^{2}$ ) the mean jet velocity scales as $U_{0}=F / A \sim F / L^{2}$, but according to the allometry of the mussel $F \sim L^{2}$ (Riisgård et al., 2014), it follows that $U_{0} \sim$ constant. Although Kumala et al. (2017) recently found that $U_{0}=F / O S A=\operatorname{constant}\left(2.3 \mathrm{~cm} \mathrm{~s}^{-1}\right)$ for a limited size range of small single-osculum sponge explants, the above scaling considerations for mussels may not apply to other filter-feeding invertebrates, such as sponges.

Sponges are modular filter-feeders that consist of one or several units, known as "aquiferous modules" (Ereskovskii, 2003; Fry, 1970, 1979). An aquiferous module is a functional unit that draws ambient water through numerous inhalant openings (ostia) into an inhalant canal system by means of pumping units (choanocyte chambers, $C C$ ) that filter the water for nutrition and then rejects it via an exhalant canal system through a single exhalant opening (osculum) to the surrounding water. Reiswig (1975) assumed a more or less constant density (within a factor of about 2) of $C C$ s in sponges (Reiswig, 1975, Table 1 therein), all delivering the same volumetric flow $(F)$. This assumption has approximately been confirmed by measurements (Riisgård et al., 1993, their Tables $1 \& 2$ for Halichondria panicea and Haliclona urceolus) suggesting $F \sim L^{3}$ (mean of $2.7 \pm 1.1$ and $2.5 \pm 1.7 \mathrm{ml} \mathrm{min}^{-1}$ ( $\mathrm{ml}$ sponge volume) $)^{-1}$, respectively). It is not known, however, how the osculum cross-sectional area $(O S A)$ scales with size. In addition, contraction behaviour exhibited by sponges may obfuscate the assessment of these allometric relationships.

Although sponges lack nervous and muscle tissues, coordinated behavioral responses to mechanical and chemical stimuli are common. The epithelium-like cell layer (pinacoderm) and myocytes (Bagby, 1966; Bergquist, 1978; Elliott and Leys, 2007; Nickel, 2004; Nickel et al., 2011) are involved in contraction, diffusible chemical messengers may be involved in coordinating the contractile behavior of sponges (Elliott and Leys, 2007, 2010; Ellwanger et al., 2007), and non-motile cilia of endopinacocytes might work as water flow sensors (Hammel et al., 2012; Ludeman et al., 2014). While contraction in sponges seems to be triggered by external stimuli such as changes in water flow, particle overloading or seasonal temperature changes 
(Leys, 2015; Patterson et al., 1997; Reiswig, 1971; Vethaak et al., 1982), spontaneous or cyclic contractions of oscula and pinacoderm have been shown to coincide with a decrease in filtration activity of the marine demosponge Halichondria panicea (Kumala et al., 2017; Riisgård et al., 2016). Under natural conditions, H. panicea is exposed to variable intensities of currents and particle loads (including re-suspended sediment; Barthel and Wolfrath, 1989).

In the present investigation, we studied single-osculum explants of Halichondria panicea experimentally. For fully expanded and actively filtering explants we determine how flow rate, exhalant jet speed and osculum cross sectional area depend on sponge size in order to explore the scaling laws of these parameters. In addition, we assessed the penetration length of the jets into the surrounding water. Our hypothesis is that both $O S A$ and $F$ increase with sponge size, but it is not clear if $U_{0}$ remains constant as observed in mussels. We further hypothesize that contractions, either spontaneous, or triggered by exposure to a neurotransmitter (GABA) or by overloading with inorganic (ink) particles, lead to decreases in $O S A, U_{0}$ and $F$ to eventually become zero as a result of hydrodynamic responses of the aquiferous (canal) system. Our results provide novel insights into basic sponge pump characteristics, emphasizing the importance of contractile behavior for controlling volume flow through a sponge module.

\subsection{Materials \& Methods}

\subsection{Cultivation of sponge explants}

Sponge explants were obtained from colonies of the demosponge Halichondria panicea in the tidal inlet of Kerteminde Fjord, Denmark. The chimneys of collected sponges were either cut in small (6 to $9 \mathrm{~mm}^{3}$ ) pieces without an osculum (cf. Kumala et al., 2017) or in fragments with a single osculum and were individually placed on substrate plates in flow-through aquaria with aerated bio-filtered seawater at a constant water temperature of $\approx 15{ }^{\circ} \mathrm{C}$. After attachment to substrate plates, sponge explants were further cultivated under the same conditions with regular addition of Rhodomonas salina algae and bacteria growing in the culture.

\subsection{Fully expanded explants}

Single-osculum Halichondria panicea explants were placed in an experimental chamber with bio-filtered seawater from flow-through cultivation tanks ( 15 to $22 \mathrm{psu}, \approx 15^{\circ} \mathrm{C}$ ). The volume of explants $\left(V_{\mathrm{s}}, \mathrm{mm}^{3}\right)$ was directly measured $\left(V_{\text {mea }}\right)$ as displaced volume of seawater when submerged in a graduated beaker or estimated as $V_{\text {est }}=\pi A^{2} / 3 h$ [Obtained from the geometry of an axisymmetric cone: $A=1 / 2 h b$, so $b=2 A / h$. $V_{\text {est }}=(\pi / 4) b^{2}(h / 3)$. Eliminate $b$ to get $\left.V_{\text {est }}=\pi A^{2} / 3 h\right]$ from video-microscope recordings of the side-view projected area $\left(A, \mathrm{~mm}^{2}\right)$, height $(h, \mathrm{~mm})$, baseline $(b, \mathrm{~mm})$ and osculum cross-sectional area $\left(O S A, \mathrm{~mm}^{2}\right)$ of the cone-shaped explants (Fig. 1). The flow speed of the exhalant jet near the osculum of fully expanded, actively filtering explants was estimated from the motion of ink particles smaller than $6 \mu \mathrm{m}$ (Pelikan Scribtol; dilution $2 \times 10^{5}$-fold to give an estimated particle density of $\left.10^{4} \mathrm{ml}^{-1}\right)$. High speed $(60.61 \mathrm{fps})$ video recordings of the particle movement in a focal (side view) plane near the exhalant jet were analyzed by particle tracking velocimetry (PTV; cf. Riisgård et al., 2011) using the software IC 
122 Capture. The exhalant jet speed, defined as the mean velocity $U_{0}$ at the osculum, was determined 123 by extrapolating the velocity field to the osculum using an exponential regression curve (Fig. 1), 124 say $U_{x} / U_{0}=\exp (-a x)$ where $U_{x}$ denotes the velocity at distance $x$ from the osculum and $a$ a constant. The penetration of the jet into the ambient water, expressed as the distance $x_{1 / 2}$ at which $U_{x} / U_{0}=1 / 2$, was calculated as $x_{1 / 2}=(\ln 2) / a$. In the present case, however, we do not know if the oscular jet-speed profile is flat or exhibit a bell shaped curve with highest velocity at the centre, as measured by Reiswig (1974) and Strehlow et al. (2016) in several sponge species. If so, $U_{0}=$ $U_{c} \times 0.9$ (profile correction factor), where $U_{c}$ is the excurrent velocity at the centerline (Reiswig, 1974). Therefore, if the extrapolated velocities fell along the centerline this would mean that the present data for $U_{0}$ may be up to $10 \%$ overestimated. But because the PTV measurements were made on particles accelerated by the jet periphery with lower velocity the error is in fact smaller.

The filtration (= flow) rate was determined as $F_{\text {est }}=O S A \times U_{0}$. The volume-specific filtration rate $F_{V}\left(=F_{\text {est }} / V_{\mathrm{s}}\right)$ was estimated as an indicator of active filter-feeding.

\subsection{Contracting explants}

Exhalant jet speed $U_{0}$ and osculum cross-sectional area $O S A$ were measured as described above, now over time during closure of the osculum of explants in bio-filtered seawater with constant mixing. This was done both during spontaneous and induced contractions after either exposure of explants to the neurotransmitter $\gamma$-aminobutyric acid (GABA, $1 \mathrm{mM}$; cf. Ellwanger et al., 2007) or after exposure to inorganic particles (Pelikan Scribtol ink; dilution $2.5 \times 10^{4}$-fold, i.e. particle density $\approx 10^{5} \mathrm{ml}^{-1}$; cf. Elliott and Leys, 2007). We comparatively estimated the response time $t_{\mathrm{c}}$ of explants, i.e. the duration of osculum closure and reduction of $U_{0}$ to zero from video recordings. Changes in in- and exhalant canal diameters $d$ during spontaneous contraction events were measured using the software ImageJ v5.0.3.

\subsection{Jet penetration and spreading. Scaling}

For the axisymmetric laminar jet, starting from a flat profile $U_{0}$ and diameter $D$ of an orifice in a plane wall, the centerline velocity $\left(U_{\mathrm{C}}\right)$ and half-width $\left(b_{1 / 2}\right)$ of the jet far downstream, which spreads the less it penetrates into the surrounding water, may be estimated from the classical theoretical solutions (Schlichting, 1968, p. 220)

where Re denotes the Reynolds number, $v\left(1.274 \times 10^{-6} \mathrm{~m}^{2} \mathrm{~s}^{-1} ; 15^{\circ} \mathrm{C}, 20 \mathrm{psu}\right.$; Riisgård and Larsen, 2009, Eq. (1) therein) the kinematic viscosity of seawater, and $x$ the distance from the osculum. For a given sponge explant of exhalant jet velocity $U_{0}$ and osculum diameter $D$, the above scaling leads to a penetration of the jet (i.e. how slowly the center velocity $U_{\mathrm{C}}$ decreases 


$$
U_{\mathrm{C}}(x) / U_{0} \approx U_{0} \times D^{2} / x ; \quad b_{1 / 2} / D \approx x /\left(U_{0} \times D^{2}\right) .
$$

For the scaling of other parameters, for fully expanded and filtering sponges, we first recall the observation (see Introduction) that choanocyte pump density, hence flow rate $F$, seems to scale directly with sponge volume, i.e. $F \sim V_{\mathrm{S}} \sim L^{3}$, where $L$ denotes a length scale of the sponge. Assuming the osculum diameter to scale as $O S A \sim L^{2}$, and using the continuity relation, $F=O S A$ $\times U_{0}$, we arrive at the scaling relations

$$
F \sim L^{3} \sim V_{\mathrm{s}} ; F \sim O S A^{3 / 2} ; U_{0}=F / O S A \sim O S A^{1 / 2}
$$

which suggest that $U_{0}$ is not constant as found for mussels.

For contracting and closing explants, say for $O S A$ decreasing to zero linearly over time $t=0$ to $t_{\mathrm{c}}$ as $O S A / O S A_{\text {start }} \sim\left(1-t / t_{\mathrm{c}}\right)$, we should expect, from Eq. (3), that jet velocity would decrease as

i.e. slowly at start but faster near full closure.

\subsection{Statistical analyses}

181 Statistical data analyses were performed in R version 3.1.3 (R Core Team 2015). Linear models 182 (LM) were parameterized to extrapolate the velocity field of moving particles to the osculum ( $x$ $183=0$ ) using exponential regression, to test for differences between estimated and measured sponge 184 explant volumes $\left(V_{\mathrm{s}}\right)$ and for fitting power functions to the relationships between osculum cross185 sectional area $(O S A)$ and $V_{\mathrm{s}}$, jet speed $\left(U_{0}\right)$ and $O S A$, filtration rate $(F)$ and $O S A$, or the distance

$186\left(x_{1 / 2}\right)$, where the center-line velocity of the exhalant jet becomes $0.5 U_{0}$, and the osculum diameter 187 (D). Model assumptions were met without the need for fitting generalized linear models. Non188 linear, asymptotic regression models (NLM) from R package 'nlstools' (Baty and Delignette189 Muller, 2015) were used to obtain comparative least-squares estimates of the parameter $U_{0}$ as a 190 function of $O S A$.

\subsection{Results}

193 For fully expanded and actively pumping explants, the experimental data for a range of osculum cross-sectional areas $\left(O S A=0.1\right.$ to $\left.3.14 \mathrm{~mm}^{2} ; n=27\right)$ show a mean volume specific filtration rate of $F_{v}=3.46 \pm 3.25 \mathrm{ml} \mathrm{min}^{-1} \mathrm{~cm}^{-3}$ (Table 1). Deviation between estimated and measured explant volumes $(n=6$; Table 1$)$ was negligible $\left(\mathrm{LM}, t_{0.3,10}=0.13, P=0.996\right)$. Obtained power-

197 law regression relations for $O S A$ versus volume $V_{\mathrm{s}}$, jet speed $U_{0}$ versus $O S A$, and pumping rate $198 F_{\text {est }}$ versus $O S A$, respectively, are in good agreement with the theoretical scaling parameters 199 (Table 2). The $O S A$ increased significantly as a function of increasing sponge volume $\left(V_{\mathrm{s}}\right)$ as 200 expressed by a power exponent 0.66 per $\mathrm{cm}^{3}$ volume increase (Fig. 2 ; LM, $t_{0.24,25}=7.2, P=1.6$ $\left.201 \times 10^{-7}\right)$. The exhalant jet speed $\left(U_{0}\right)$ increased significantly with increasing $O S A$ as indicated by a 
202

203

204

205

206

207

208

209

210

211

212

213

214

215

216

217

218

219

220

221

222

223

224

225

226

227

228

229

230

231

232

233

234

235

236

237

238

239

240

241

power function with the exponent 0.45 (Fig. 3 ; LM, $t_{0.16,25}=5.8, P=5.4 \times 10^{-6}$ ). For the investigated range of $O S A$ s (Table 1), $U_{0}$ reached a maximum value of $5.3 \mathrm{~cm} \mathrm{~s}^{-1}$ (Fig. 3). Note that parameters $F, O S A$ and $U_{0}$ are not independent but related by continuity of flow, $F=O S A \times$ $U_{0}\left(\sim O S A^{1+0.45}\right)$, where the estimated filtration rate $\left(F_{\text {est }}\right)$ increased with increasing $O S A$ (Fig. 4) according to a power function with the exponent $1.45\left(\mathrm{LM}, t_{0.16,25}=18.6, P=3.6 \times 10^{-16}\right)$.

Figure 5 shows how the distance $\left(x_{1 / 2}\right)$ where center velocity of jet has decreased to half its initial value $\left(U_{\mathrm{C}}=0.5 U_{0}\right)$ increases with increasing osculum diameter $(D)$ as indicated by a power function with the exponent $1.48\left(\mathrm{LM}, t_{0.23,25}=6.6, P=6.5 \times 10^{-7}\right)$. The dependence on jet penetration $\left(x_{1 / 2}\right)$ on jet velocity (not shown) appears to show somewhat more scatter, but is approximately $x_{1 / 2} \sim U_{0}^{0.99}\left(\mathrm{LM}, t_{0.30,25}=4.1, P=3.6 \times 10^{-4}\right)$.

The experimentally measured decrease of jet velocity with distance from osculum (Fig. 1) follow an exponential relationship rather than the theoretical $1 / x$ suggested by Eq. (2). The jet penetration length expressed by $x_{1 / 2}$ is relatively long, dependet on the size of the sponge explant (Table 1). [Data on half-width of jet $b_{1 / 2}$ is missing?]

Long-term time-lapse video recordings of an initially fully expanded explant (ID \#7, Table 1; Video 1 in the Supplement) revealed repeated spontaneous contractions over time, despite otherwise undisturbed conditions. The different stages of a spontaneous contraction in the same single-osculum explant (Fig. 6) start from normal flow, visualized with fluorescein dye (Fig. 6A), through expanded excurrent canals (Fig. 6B). As the osculum closes within a response time of $t_{\mathrm{c}}=38 \pm 8 \mathrm{~min}$ (Figs. 6C-D \& 7A), the endopinacoderm lining constricts the excurrent canals by up to $87.1 \pm 2.7 \%$ (Fig. 7B, arrows) which may effectively restrict or stop the water flow. Exposure to GABA $(1 \mathrm{mM})$ triggered contractions in selected $H$. panicea explants $(n=6$; cf. Table 1) and they were correlated with decreases in both $O S A$ and exhalant jet speed $U_{0}$ to eventually become zero within a mean response time $t_{\mathrm{c}}=23 \pm 7 \mathrm{~min}$ (Figs. $8 \&$ 9). Besides chemical stimulation by the addition of GABA (Video 2 in the Supplement), overloading with inorganic ink particles (particle density $\approx 10^{5} \mathrm{ml}^{-1}$ ) was found to trigger contractions with subsequent cessation of the pumping rate in within $t_{\mathrm{c}} \approx 50 \mathrm{~min}$ (Video 3 in the Supplement).

\subsection{Discussion}

The data for expanded and actively pumping explants in Table 1 are ordered in terms of increasing osculum area $O S A$ and show a corresponding increase in jet velocity $U_{0}$ and the related filtration rate $F$ (Figs. $3 \& 4$ ). The observed trend of an increase in exhalant jet speed $U_{0}$ with increasing osculum cross-sectional area OSA (Fig. 3) in Halichondria panicea explants extends to larger sponges with identical power exponent of 0.45 as appears from a comparison to literature values (Fig. 10; LM, $t_{0.17,31}=7.6, P=1.6 \times 10^{-8}$ ). For various sponge species with $O S A \mathrm{~s}$ in the range 0.1 to $7 \mathrm{~mm}^{2}, U_{0}$ seems to reach a maximum of $U_{0}=6$ to $8 \mathrm{~cm} \mathrm{~s}^{-1}$ (Table 3 ; Reiswig, 1974; Strehlow et al., 2016).

The hypothesis of a more or less constant density of choanocyte chambers in sponges, all delivering the same volume flow, is supported by the power law of Fig. $3\left(U_{0} \sim O S A^{0.45}\right)$ that, along with continuity of flow $\left(F=O S A \times U_{0}\right)$, leads to $F \sim O S A \times O S A^{0.45}=O S A^{1.45} \sim L^{2.9} \sim V_{\mathrm{s}}$. 
Although a forced linear regression of the data of Fig. 2 (i.e. a power-law exponent of 1.0 instead of $0.66=2 / 3$ found by free regression) would lead to a higher $\mathrm{R}^{2}$-value, it contradicts dimensional scaling, hence not considered likely. Values of the volume-specific filtration rate $F_{V}$ $\left(=F / V_{\mathrm{s}}\right)$ for individual explants listed in Table 1 show large variations and an arithmetic mean of $F_{V}(\mathrm{ml} \mathrm{min}-1) \approx 3.46 \pm 3.25 V_{\mathrm{s}}\left(\mathrm{cm}^{3}\right)$ which may be explained by strong temporal dynamics in the expansion state of explants (Video 1 in Supplement). A more objective correlation-smoothed mean value is obtained from the relations $O S A=1.31 V_{\mathrm{s}}^{0.66}$ (Fig. 2) and $F=1.55 O S A^{1.45}$ (Fig. 4), which after elimination of $O S A$ gives $F(\mathrm{ml} \mathrm{min}-1) \approx 2.3 V_{\mathrm{s}}\left(\mathrm{cm}^{3}\right)$ and is in good agreement with previous findings (Larsen and Riisgård, 1994; Riisgård et al., 1993). This relation may be compared to data for Haliclona urceolus (Larsen and Riisgård, 1994, Table 1 therein), giving a filtration rate $F=6 \mathrm{ml} \mathrm{min}{ }^{-1}$ for a sponge volume $V_{\mathrm{s}}\left[=3.2 \times \pi\left(0.86^{2}-0.23^{2}\right) / 4\right]=1.73 \mathrm{~cm}^{3}$, or $F$ $(\mathrm{ml} \mathrm{min}-1) \approx 3.5 V_{\mathrm{s}}\left(\mathrm{cm}^{3}\right)$. The two constants (2.3 and 3.5) must represent the number of choanocyte chambers $(C C)$ per unit volume times the average filtration rate of one $C C$. It is remarkable that the volume-specific filtration rate is of the same order of magnitude for the two sponge species as it likely suggests choanocyte chambers of similar size, with similar individual filtration rate, and of similar uniform distribution over the sponge volume. This also supports the hypothesis of volumetric scaling (cf. Table 2).

Turning to the question of penetration and spreading of the exhalant jet into the surrounding water, the decrease of jet velocity with distance from osculum ( $x$; Fig. 1) appears to follow an exponential relationship rather than $1 / x$ as suggested by Eq. (2). Also, our data show that $x_{1 / 2} \sim$ $D^{1.48}$ (Fig. 5) rather than $x_{1 / 2} \sim U_{0} D^{2}$ (Eq. 2) or $x_{1 / 2} \sim D^{3}$ for $U_{0} \sim O S A^{0.45} \sim D$ (Table 2). One reason is that the boundary layer assumption ( $\operatorname{Re}>>1)$ implicit in the solutions of Eq. (1) is not satisfied for the low Reynolds number at hand (mean of 16.8 for the 27 sponge explants), or that the initial velocity profile is not flat (but see Lee et al., 1997) or that the fictive origin of the solution is upstream of $x=0$ (but see Revuelta et al., 2002). However, it is noted that the jet penetration is considerable. For the small explant ID \#1 of height $h=3.8 \mathrm{~mm}$, for example, $x_{1 / 2}=$ $2.3 \mathrm{~mm}$ (Table 1) but organized flow due to the jet reaches much further out into the otherwise quiescent water (see Fig. 1), so that sponges avoid re-circulation of already filtered water (Bidder, 1923; Riisgård and Larsen, 2017).

For the experiments on contracting explants in response to exposure to GABA, OSA typically decreases nearly linearly to zero within the mean response time $t_{\mathrm{c}}$. The corresponding exhalant jet velocity (Fig. 9) shows more scatter and a tendency to slowly decrease at the start and accelerate towards the end, as suggested by Eq. (4). This is particularly evident for ID \#16 (Fig. 9B). As known from an experiment on the back-pressure characteristics of sponges (Riisgård et al., 1993), the choanocyte pumps continue to operate as net flow is reduced to zero, at which time pumps deliver a pressure more than 3 times as high as at their normal operating pump pressure. Internal leakage within the pumps makes this possible. As osculum and canals begin to contract, the choanocytes merely raise their delivered pressure in an attempt to maintain flow, so that jet velocity would decrease slowly at start, as suggested by Eq. (4). Therefore, even during complete osculum closure, the choanocyte pumps may continue to operate as leaky peristaltic 
pumps (Larsen \& Riisgård, 1994). The rate of osculum expansion after a period of closure appears to be as high as the rate of decrease toward closure (Fig. 7A) which indicates that accompanying changes in exhalant jet velocity are reversible.

The duration of osculum closure was in a similar range among spontaneous and GABA- or particle-triggered contractions in explants (Videos 1 to 3 in Supplement). It is seen that the mean autonomous closing time of $t_{c}=38 \pm 8$ min during spontaneous contractions (Fig. 7) is somewhat longer than the GABA-triggered response time of $t_{c}=23 \pm 7$ (Fig. 9) which may be due to an applied concentration of the neurotransmitter $(1 \mathrm{mM})$ above physiological levels (Elliott and Leys, 2010; Ellwanger et al., 2007). The observed osculum response times are comparable with the duration of spontaneous ( $t_{c} \approx 23 \mathrm{~min}$; Nickel, 2004, Table 1 therein) and chemically induced choanosome contractions in Tethya wilhelma $\left(t_{c} \approx 15 \mathrm{~min}\right.$ after exposure to 1 mM GABA; Ellwanger et al., 2007, their Fig. 5). The response time after exposure to inorganic particles (dilution $2.5 \times 10^{4}$-fold) was somewhat extended to $t_{c} \approx 50$ min compared to spontaneous contractions. This is in agreement with previous observations that overloading with inorganic particles slows down the contraction cycle in the freshwater sponge Ephydatia muelleri ( $t_{c} \approx 17$ min after exposure to $4 \times 10^{3}$-fold diluted ink particles; Elliott and Leys, 2007) which uses coordinated peristaltic waves to expel water and waste material from its aquiferous system. Our findings suggest contractile behavior as an important mechanism to avoid overloading of the sponge pump with inorganic particles, while cellular transport seems to regulate the removal of particles from the aquiferous system of $H$. panicea (Video 3 in Supplement). While sponges seem to use their pinacoderm for mediating contractions via sensory systems, signaling pathways and actinocytes as effectors (Leys, 2015; Nickel et al., 2011), it remains to determine the mechanisms that control contractions. A volumetric contraction of an explant would likely reduce diameters of the canal system and hence lower the filtration rate, but this in itself would not stop the choanocyte pumps.

As previously elaborated by Kumala et al. (2017), several previous observations suggest various forms of sensing control of flow and contraction, including the regulation of the choanocyte pumps. Kumala et al. (2017) found the relationship $F\left(\mathrm{ml} \mathrm{min}^{-1}\right)=1.39 \times O S A\left(\mathrm{~mm}^{2}\right)$ to be a good approximation for single-osculum $H$. panicea explants with $O S A<0.5 \mathrm{~mm}^{2}$, which does not essentially contradict the present data (Fig. 4). Their data did not justify other regression analysis but the linear one for the limited size range investigated.

For the data shown in Figs. $3 \& 10$, an exponential regression curve of form $U_{0}=U_{\max }[1-$ $\left.\exp \left(-O S A / O S A_{0}\right)\right]$ has also been considered, leading to asymptotic maximal values $U_{\max } \approx 4.1$ $\mathrm{mm} \mathrm{s}^{-1}\left(\mathrm{NLM}, t_{0.77,25}=7.2, P=1.6 \times 10^{-7}\right)$ and $\approx 6.3 \mathrm{~mm} \mathrm{~s}^{-1}\left(\mathrm{NLM}, t_{1.22,32}=7.6, P=1.3 \times 10^{-8}\right)$, respectively. This may indicate that the exhalant jet speed of a single-osculum sponge explant, or the jet speed from an individual osculum in a multi-oscula sponge, approaches a certain upper limit as the sponge grows, and further that an aquiferous module of a multi-oscula sponge supplying a specific osculum with water may increase to a certain size, after which the sponge pump may become insufficient for the increasing system head loss, so that instead a new small module with an initially small $O S A$ is formed. We offer the following possible explanation based 
on the earlier mentioned indication that the volume-specific density of choanocyte chambers $(C C)$ is approximately constant among sponges. This would imply that the fraction of total volume occupied by $C C$ s would be independent of size, $V_{\mathrm{s}, \mathrm{CC}} \sim c_{1} V_{\mathrm{s}}$ where $c_{1}$ is a constant $<1$. The number of canals (at least the smaller branching ones) servicing $C C$ s is proportional to their number, hence the canal volume is proportional to $V_{\mathrm{s}}$. In addition, the volume taken up by the larger inhalant and exhalant canals is a summation over their cross-sectional areas $\pi r_{\mathrm{i}}{ }^{2}$ and lengths $L_{\mathrm{i}},\left(\sim \sum \pi r_{\mathrm{i}}^{2} L_{\mathrm{i}} \sim V_{\mathrm{s}}^{1 / 3}\right)$ based on the assumption that the distribution of radii $r$ over canal sections is approximately independent of sponge size. Therefore the fraction of volume occupied by canals would depend on sponge volume as $V_{\mathrm{s} \text {,canals }} \sim V_{\mathrm{s}} \times V_{\mathrm{s}}^{1 / 3} \sim V_{\mathrm{s}}^{4 / 3}$, hence an increasing part of the sponge volume, which suggests that single-osculum aquiferous modules may be sizelimited. The increase in frictional head loss in canals as their lengths increases (as $L \sim V_{\mathrm{s}}{ }^{1 / 3}$ ) would tend to lower the filtration rate even though $C C$-pumps can deliver the associated pressure rise. On the other hand, if a sponge develops a large atrium its total volume may still continue to increase since not all canals must merge into a single large exhalant canal terminating at the osculum, but then many large canals can terminate at the atrium. While our findings emphasize the importance of contractile behavior for the pumping activity of the leuconoid demosponge $H$. panicea, future studies on the comparative functional morphology of sponges at different levels of organization (ascon, sycon, or leucon; cf. Ereskovskii, 2003) may shed further light on purpose and function of the 'sponge neural toolkit' (Leys, 2015), including sensory cells, conduction pathways and signaling molecules. Finally, it is of interest to test if our hypothesis of near constant volume-specific filtration rate and possibly also density of choanocyte chambers would apply to other species of leuconoid sponges.

\section{Acknowledgements}

This work was supported by a research grant (9278) from VILLUM FONDEN. We are grateful to two anonymous reviewers for providing valuable feedback on the manuscript.

\section{Supplementary data}

Supplementary video material to this article can be found online at $\mathrm{xxx}$.

\section{References}

Bagby, R.M. 1966. The fine structure of myocytes in the sponges Microciona prolifera (Ellis and Solander) and Tedania ignis (Duchassaing and Michelotti). J. Morphol. 118, 167-181.

Barthel, D., Wolfrath, B. 1989. Tissue sloughing in the sponge Halichondria panicea: a fouling organism prevents being fouled. Oecologia 78, 357-360.

Baty, F., Delignette-Muller, M. L. 2015. Package 'nlstools': tools for nonlinear regression analysis. http://cran.r-project.org/web/packages/nlstools.

Bergquist, P.R. 1978. Sponges. University of California Press, Berkeley.

Bidder, G.P. 1923. The relation of the form of a sponge to its currents. Q. J. Microsc. Sci. 67, 293-323. 
Elliott, G.R.D., Leys, S.P. 2007. Coordinated contractions effectively expel water from the aquiferous system of a freshwater sponge. J. Exp. Biol. 210, 3736-3748.

Elliott, G.R.D., Leys, S.P. 2010. Evidence for glutamate, GABA and NO in coordinating behaviour in the sponge, Ephydatia muelleri (Demospongiae, Spongillidae). J. Exp. Biol. 213, 2310-2321.

Ellwanger, K., Eich, A., Nickel, M. 2007. GABA and glutamate specifically induce contractions in the sponge Tethya wilhelma. J. Comp. Physiol. A 193, 1-11.

Ereskovskii, A.V. 2003. Problems of coloniality, modularity, and individuality in sponges and special features of their morphogeneses during growth and asexual reproduction. Russ. J. Mar. Biol. 29, 46-56.

Fry, W.G. 1970. The sponge as a population: a biometric approach. Symp. Zool. Soc. London 25, 135-162.

Fry, W.G. 1979. Taxonomy, the individual and the sponge. Biology and Systematics of Colonial organisms. Syst. Ass. Special 11, 49-80.

Hammel, J.U., Filatov, M.V., Herzen, J., Beckmann, F., Kaandorp, J.A., Nickel, M. 2012. The non-hierarchical, non-uniformly branching topology of a leuconoid sponge aquiferous system revealed by $3 \mathrm{D}$ reconstruction and morphometrics using corrosion casting and X-ray microtomography. Acta Zool. 93, 160-170.

Kumala, L., Riisgård, H.U., Canfield, D.E. 2017. Osculum dynamics and filtration activity studied in small single-osculum explants of the demosponge Halichondria panicea. Mar. Ecol. Prog. Ser. 572, 117-128.

Larsen, P.S., Riisgård, H.U. 1994. The sponge pump. J. Theor. Biol. 168, 53-63.

Lee, S., Kihm, K.D., Chung, S.H. 1997. Analytical solutions for the developing jet from a fullydeveloped laminar tube flow. J. Fluids. Eng. 119, 716-718.

Leys, S.P. 2015. Elements of a 'nervous system' in sponges. J. Exp. Biol. 218, 581-591.

Ludeman, D.A., Farrar, N., Riesgo, A., Paps, J., Leys, S.P. 2014. Evolutionary origins of sensation in metazoans: functional evidence for a new sensory organ in sponges. BMC Evol. Biol. 14, 3.

Nickel, M. 2004. Kinetics and rhythm of body contractions in the sponge Tethya wilhelma (Porifera: Demospongiae). J. Exp. Biol. 207, 4515-4524.

Nickel, M., Scheer, C., Hammel, J.U., Herzen, J., Beckmann, F. 2011. The contractile sponge epithelium sensu lato - body contraction of the demosponge Tethya wilhelma is mediated by the pinacoderm. J. Exp. Biol. 214, 1692-1698.

Patterson, M.R., Chernykh, V.I., Fialkov, V.A., Savarese, M. 1997. Trophic effects of sponge feeding within Lake Baikal's littoral zone. 1. In situ pumping rates. Limnol. Oceanogr. 42, 171-178.

R Core Team 2015. R: A language and environment for statistical computing. R Foundation for Statistical Computing, Vienna, Austria. http://www.R-project.org/.

Reiswig, H.M. 1971. In situ pumping activities of tropical Demospongiae. Mar. Biol. 9, 38-50. 
401

402

403

404

405

406

407

408

409

410

411

412

413

414

415

416

417

418

419

420

421

422

423

424

425

426

427

428

429

430

431

432

Reiswig, H.M. 1974. Water transport, respiration and energetics of three tropical marine sponges. J. Exp. Mar. Biol. Ecol. 14, 231-249.

Reiswig, H.M. 1975. The aquiferous systems of three marine Demospongiae. J. Morphol. 145, 493-502.

Revuelta, A., Sánchez, A.L., Liñán, A. 2002. The virtual origin as a first-order correction for the far-field description of laminar jets. Phys. Fluids 14, 1821-1824.

Riisgård, H.U., Jørgensen, B.H., Lundgreen, K., Storti, F., Walther, J.H., Meyer, K.E., Larsen, P.S. 2011. The exhalant jet of mussels Mytilus edulis. Mar. Ecol. Prog. Ser. 437, 147-164.

Riisgård, H.U., Kumala L., Charitonidou K. 2016. Using the F/R-ratio for an evaluation of the ability of the demosponge Halichondria panicea to nourish solely on phytoplankton versus free-living bacteria in the sea. Mar. Biol. Res. 12, 907-916.

Riisgård, H.U., Larsen, P.S. 2009. Ciliary-propelling mechanism, effect of temperature and viscosity on swimming speed, and adaptive significance of 'jumping' in the ciliate Mesodinium rubrum. Mar. Biol. Res. 5, 585-595.

Riisgård, H.U., Larsen, P.S. 2017. Filter-feeding zoobenthos and hydrodynamics, in: Rossi, S., Bramanti, L., Gori, A., Orejas, C. (Eds.), Marine animal forests. The ecology of benthic biodiversity hotspots. Springer, pp. 787-811.

Riisgård, H.U., Larsen, P.S., Pleissner, D. 2014. Allometric equations for maximum filtration rate in blue mussels Mytilus edulis and importance of condition index. Short communication, Helgol. Mar. Res. 68, 193-198.

Riisgård, H.U., Thomassen, S., Jakobsen, H., Weeks, J.M., Larsen, P.S. 1993 Suspension feeding in marine sponges Halichondria panicea and Haliclona urceolus: effects of temperature on filtration rate and energy cost of pumping. Mar. Ecol. Prog. Ser. 96, 177-188.

Schlichting, H. 1968. Boundary layer theory. McGraw-Hill Book Company, New York

Strehlow, B.W., Jorgensen, D., Webster, N.S., Pineda, M.C., Duckworth, A. 2016. Using a thermistor flowmeter with attached video camera for monitoring sponge excurrent speed and oscular behaviour. PeerJ 4:e2761, https://doi.org/10.7717/peerj.2761.

Vethaak, A.D., Cronie, R.J.A., Van Soest, R.W.M. 1982. Ecology and distribution of two sympatric, closely related sponge species, Halichondria panicea (Pallas, 1766) H. bowerbanki Burton, 1930 (Porifera, Demospongiae), with remarks on their speciation. Contrib. Zool. 52, 82-102.

Vogel, S. 1994. Life in moving fluids. The physical biology of flow. Princeton University Press 
433 Table 1. Halichondria panicea. Characteristics of single-osculum sponge explants. OSA:

434 osculum cross-sectional area; $A$ : projected area; $h$ : height; $V_{\text {est }}\left[=\pi \mathrm{A}^{2} / 3 \mathrm{~h}\right]$ : estimated volume;

$435 V_{\text {mea }}$ : measured volume; $U_{0}$ : exhalant jet speed at distance $x=0 \mathrm{~mm}$ from osculum (cf. Fig. 1);

$436 x_{1 / 2}$ : distance where center velocity of jet $U_{\mathrm{C}}=0.5 U_{0} ; F_{\text {est }}\left[=O S A \times U_{0}\right]$ : estimated filtration rate;

$437 \quad F_{V}\left[=F_{\text {est }} / V_{\text {est }}\right.$, or when possible $\left.=F_{\text {est }} / V_{\text {mea }}\right]:$ volume-specific filtration rate.

\begin{tabular}{|c|c|c|c|c|c|c|c|c|c|}
\hline $\begin{array}{c}D \\
\#\end{array}$ & $\begin{array}{c}O S A \\
\left(\mathrm{~mm}^{2}\right)\end{array}$ & $\begin{array}{c}A \\
\left(\mathrm{~mm}^{2}\right)\end{array}$ & $\begin{array}{c}h \\
(\mathrm{~mm})\end{array}$ & $\begin{array}{c}V_{\text {est }} \\
\left(\mathrm{mm}^{3}\right)\end{array}$ & $\begin{array}{c}V_{\text {mea }} \\
\left(\mathrm{mm}^{3}\right)\end{array}$ & $\begin{array}{c}U_{0} \\
\left(\mathrm{~mm} \mathrm{~s}^{-1}\right)\end{array}$ & $\begin{array}{c}x_{1 / 2} \\
(\mathrm{~mm})\end{array}$ & 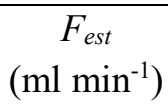 & 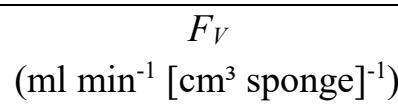 \\
\hline 1 & 0.10 & 10.8 & 3.8 & 32 & - & 6.6 & 2.3 & 0.04 & 1.23 \\
\hline 2 & 0.14 & 6.5 & 3.2 & 14 & - & 5.9 & 2.2 & 0.05 & 3.64 \\
\hline 3 & 0.15 & 30.6 & 7.0 & 139 & - & 6.6 & 2.3 & 0.06 & 0.43 \\
\hline 4 & 0.17 & 54.6 & 12.0 & 259 & - & 10.7 & 3.1 & 0.11 & 0.42 \\
\hline 5 & 0.20 & 14.3 & 4.4 & 49 & - & 13.7 & 2.4 & 0.16 & 3.39 \\
\hline 6 & 0.20 & 34.5 & 7.8 & 159 & - & 14.0 & 5.1 & 0.17 & 1.05 \\
\hline 7 & 0.24 & 25.9 & 4.3 & 164 & - & 23.4 & 5.3 & 0.34 & 2.05 \\
\hline 8 & 0.25 & 22.4 & 5.5 & 95 & - & 30.8 & 3.7 & 0.46 & 4.89 \\
\hline 9 & 0.28 & 38.5 & 9.2 & 169 & - & 14.9 & 6.4 & 0.25 & 1.48 \\
\hline 10 & 0.28 & - & - & - & 132 & 21.1 & 7.1 & 0.35 & 2.69 \\
\hline 11 & 0.35 & 51.3 & 14.5 & 191 & 136 & 24.4 & 6.9 & 0.51 & 3.77 \\
\hline 12 & 0.37 & 52.9 & 10.9 & 268 & - & 18.7 & 6.8 & 0.41 & 1.54 \\
\hline 13 & 0.37 & 42.4 & 7.4 & 256 & - & 10.8 & 6.5 & 0.24 & 0.94 \\
\hline 14 & 0.48 & 53.5 & 10.4 & 289 & - & 11.0 & 2.5 & 0.32 & 1.10 \\
\hline 15 & 0.59 & 66.2 & 6.0 & 766 & 811 & 17.1 & 41.0 & 0.60 & 0.74 \\
\hline 16 & 0.60 & 33.9 & 8.0 & 151 & - & 25.9 & 9.0 & 0.93 & 6.16 \\
\hline 17 & 0.61 & 44.0 & 9.8 & 207 & - & 15.2 & 7.8 & 0.56 & 2.69 \\
\hline 18 & 0.68 & - & - & - & 183 & 25.2 & 14.8 & 1.03 & 5.64 \\
\hline 19 & 0.68 & 65.5 & 12.8 & 351 & 346 & 33.9 & 5.9 & 1.38 & 4.00 \\
\hline 20 & 0.89 & 36.9 & 11.1 & 128 & 95 & 27.8 & 5.0 & 1.48 & 15.63 \\
\hline 21 & 1.01 & 100.4 & 13.0 & 810 & 838 & 24.4 & 19.3 & 1.48 & 1.77 \\
\hline 22 & 1.13 & - & - & - & 528 & 23.9 & 36.7 & 1.62 & 3.07 \\
\hline 23 & 1.13 & - & - & - & 411 & 39.5 & 17.4 & 2.68 & 6.51 \\
\hline 24 & 1.69 & 66.1 & 13.1 & 347 & 374 & 34.4 & 10.3 & 3.49 & 9.33 \\
\hline 25 & 2.36 & - & - & - & 1591 & 20.2 & 25.5 & 2.86 & 1.80 \\
\hline 26 & 2.54 & - & - & - & 1899 & 31.5 & 17.9 & 4.81 & 2.53 \\
\hline 27 & 3.14 & - & - & - & 1977 & 53.0 & 24.7 & 9.98 & 5.05 \\
\hline & & & & & & & \multicolumn{2}{|c|}{ Mean \pm S.D. } & $3.46 \pm 3.25$ \\
\hline
\end{tabular}


438 Table 2. Theoretical and observed scaling of sponge volume $V_{\mathrm{s}}$, osculum cross-sectional area $439 O S A$, exhalant jet speed $U_{0}$ and filtration rate $F$.

\begin{tabular}{ccc}
\hline Figure & Theoretical scaling & Observed scaling \\
\hline 2 & $O S A \sim V_{\mathrm{s}}^{2 / 3}$ & $O S A \sim V_{\mathrm{s}}^{0.66}$ \\
3 & $U_{0} \sim O S A^{1 / 2}$ & $U_{0} \sim O S A^{0.45}$ \\
4 & $F \sim O S A^{3 / 2}$ & $F_{\text {est }} \sim O S A^{1.45}$ \\
\hline
\end{tabular}


440 Table 3. Measured exhalant jet speed $\left(U_{0}\right)$, osculum diameter $(D)$, osculum cross-sectional area

$441(O S A)$, Reynolds number $\left(\operatorname{Re}=U_{0} D / v\right)$, and sample size $(n)$ of various sponge species.

\begin{tabular}{lcccccl}
\hline Species & $\begin{array}{c}U_{0} \\
\left(\mathrm{~mm} \mathrm{~s}^{-1}\right)\end{array}$ & $\begin{array}{c}D \\
(\mathrm{~mm})\end{array}$ & $\begin{array}{c}\text { OSA } \\
\left(\mathrm{mm}^{2}\right)\end{array}$ & $\begin{array}{c}n \\
\text { (ind.) }\end{array}$ & Reference \\
\hline Mycale sp. & 79 & 2.1 & 3.42 & 130 & 13 & Reiswig (1974) \\
Verongia gigantea & 128 & 1.0 & 0.78 & 100 & 11 & Reiswig (1974) \\
Tethya crypta & 173 & 1.2 & 1.04 & 157 & 8 & Reiswig (1974) \\
Haliclona permollis & 51 & 2.8 & 6.16 & 113 & 2 & Reiswig (1975) \\
Haliclona urceolus & 56 & 1.5 & 1.77 & 66 & 8 & Riisgård et al. (1993) \\
Baikalospongia bacillifera & 33 & 3.0 & 6.84 & 77 & 2 & Patterson et al. (1997) \\
Cliona orientalis & 61 & 2.1 & 3.60 & 103 & 2 & Strehlow et al. (2016) \\
Halichondria panicea & 23 & 0.7 & 0.38 & 13 & 7 & Kumala et al. (2017) \\
Halichondria panicea & 22 & 1.0 & 0.76 & 17 & 27 & This study \\
\hline
\end{tabular}




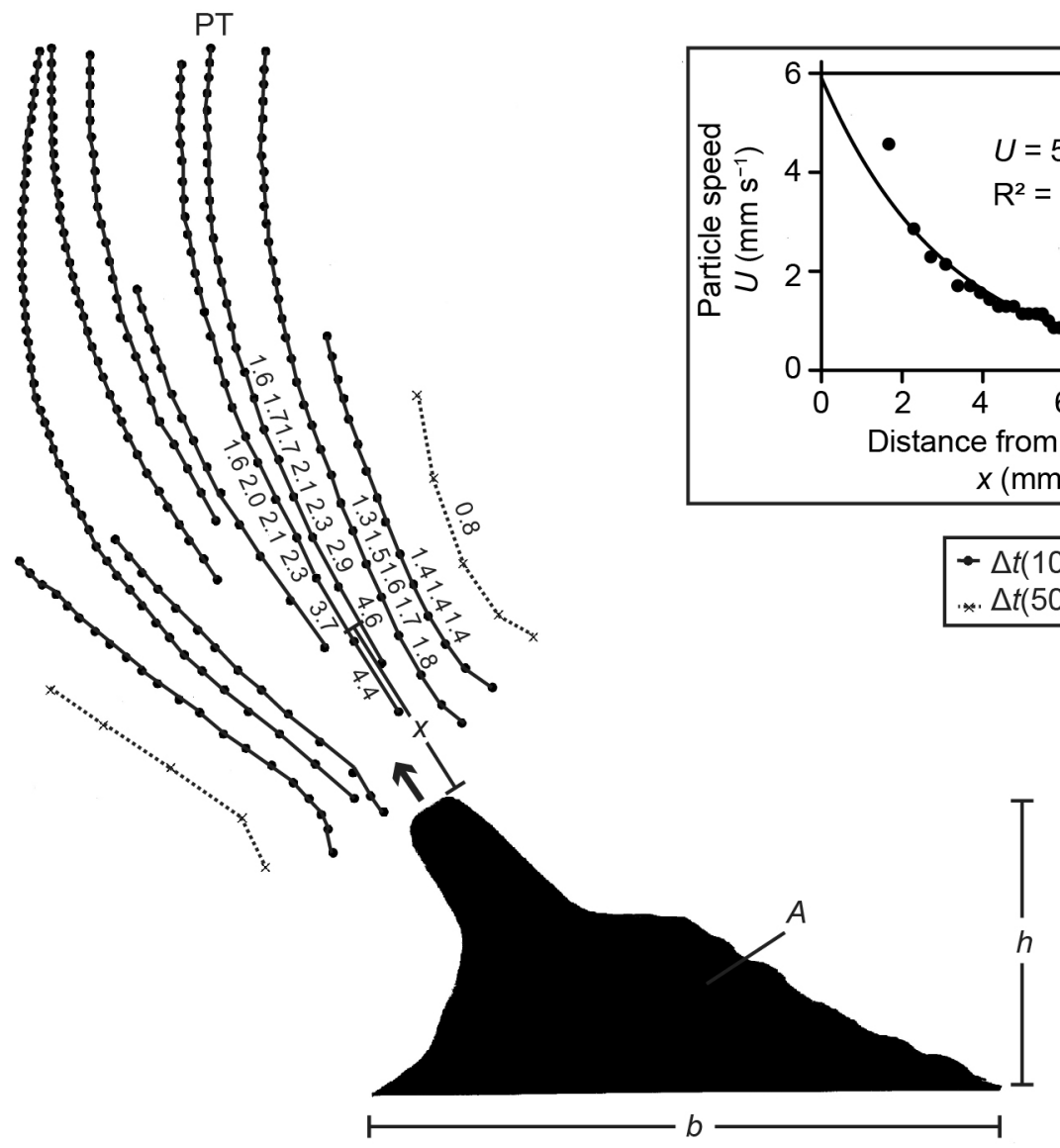

Figure 1. Halichondria panicea. Flow pattern and speed of tracer particles accelerated by the (particle-free) exhalant jet of a single-osculum sponge explant (ID \#2, Table 1). Ink particles $(2 \times$ $10^{5}$-fold dilution) were traced over 10 - $(\bullet)$ or 50 -frame $(\times)$ intervals $(\Delta t$; from $60.61 \mathrm{fps}$ video recordings) to obtain shown particle speeds $\left(\mathrm{mm} \mathrm{s}^{-1}\right)$. Projected area $A$, baseline $b$ (assumed equal to diameter of base area) and height $h$ were used to calculate the explant volume. Insert: Particle speed $U$ versus distance $x$ from osculum in one particle trace (PT; maximum observed speed $\left.U_{\max }=4.6 \mathrm{~mm} \mathrm{~s}^{-1}\right)$. The exponential regression function $U_{\mathrm{C}} / U_{0}=\exp (-a x)\left(\mathrm{LM}, t_{0.04,23}=\right.$ $\left.-23.2, P<2 \times 10^{-16}\right)$ indicates an exhalant jet speed $U_{0}=5.9 \mathrm{~mm} \mathrm{~s}^{-1}$ at $x=0 \mathrm{~mm}$ for $a=0.32 \mathrm{~s}^{-1}$, and $x_{1 / 2}=(\ln 2) / a=2.2 \mathrm{~mm}$. Scale bar: $1 \mathrm{~mm}$. 


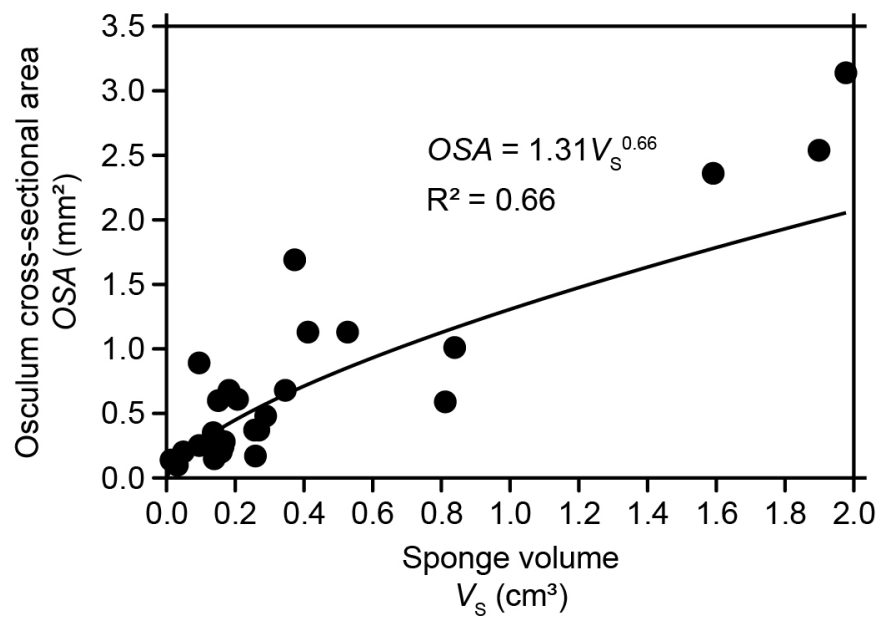

Figure 2. Halichondria panicea. Osculum cross-sectional area (OSA) as a function of sponge 454 explant volume $\left(V_{\mathrm{s}}\right)$. 


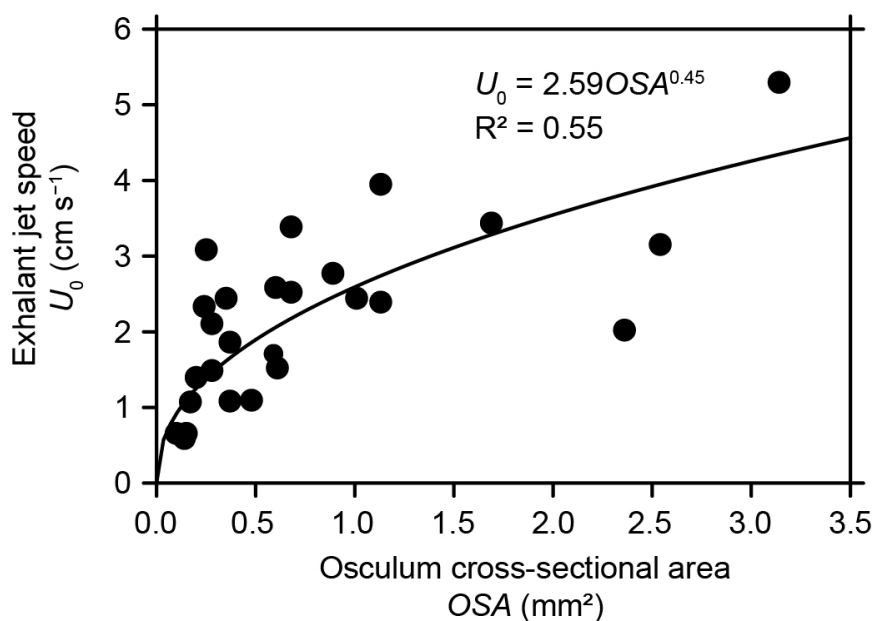

456 Figure 3. Halichondria panicea. Exhalant jet speed $\left(U_{0}\right)$ of single-osculum explants as a 457 function of the osculum cross-sectional area $(O S A)$. 


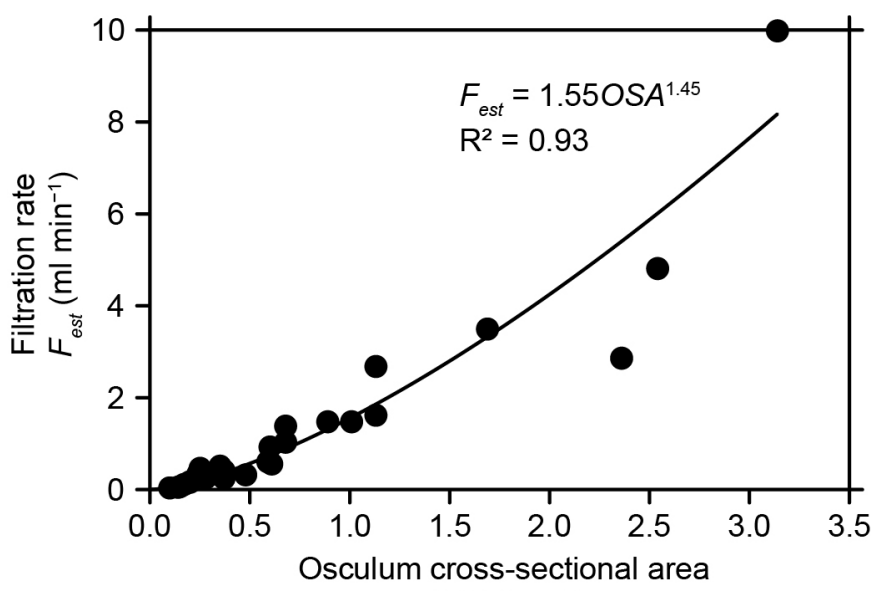
OSA $\left(\mathrm{mm}^{2}\right)$

459 Figure 4. Halichondria panicea. Estimated filtration rate $\left(F_{\text {est }}=O S A \times U_{0}\right)$ as a function of 460 osculum cross-sectional area (OSA). 


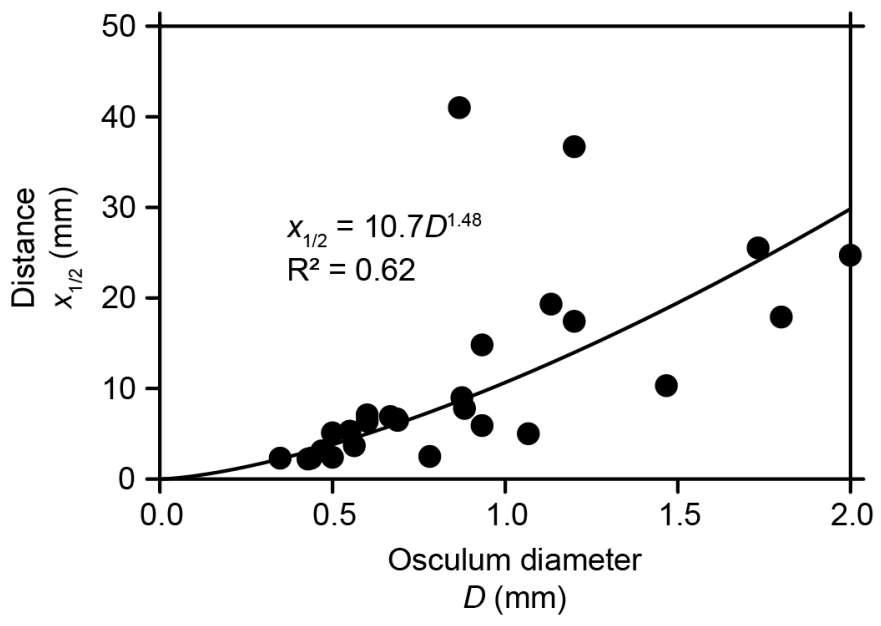

461

462

463

Figure 5. Halichondria panicea. Distance $\left(x_{1 / 2}\right)$ where center velocity of jet $U_{\mathrm{C}}=0.5 U_{0}$ as a function of osculum diameter $(D)$. 


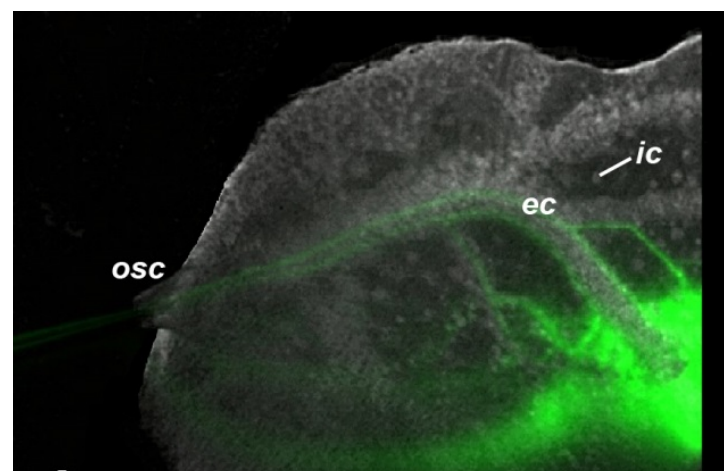

A

- B

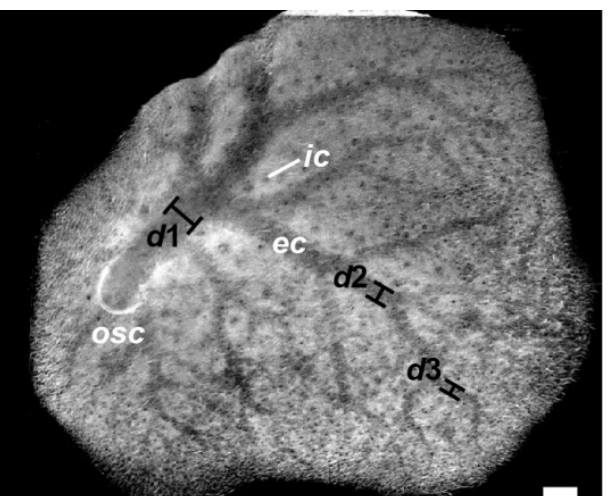

C

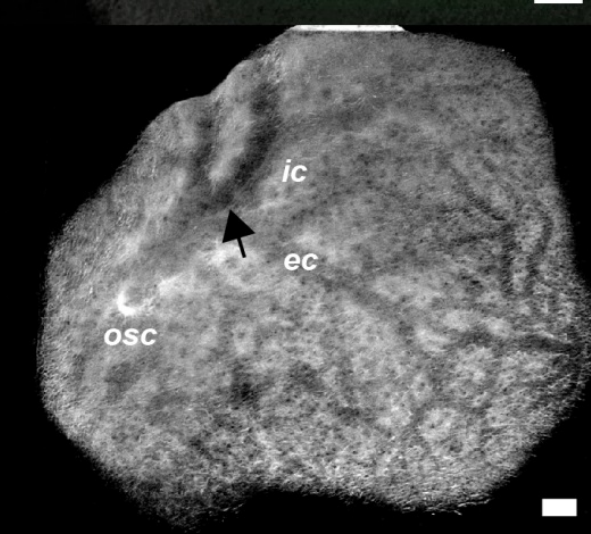

D

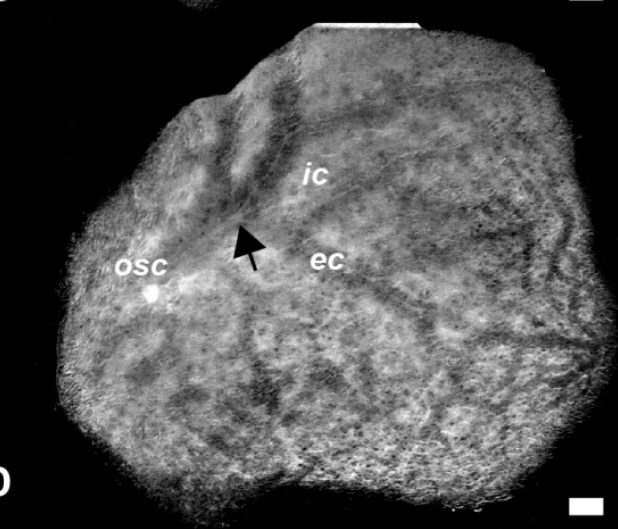

Figure 6. Halichondria panicea. (A) Close-up of a single-osculum explant (ID \#7, Table 1) showing flow through the excurrent canals (ec) and osculum (osc) after uptake of green fluorescent dye from the ambient seawater via incurrent canals ( $i c$; visible from top view, diameter $\sim 200 \mu \mathrm{m}$ ). (B-D) Different stages of a spontaneous contraction in the explant during long-term observation (Video 1 in Supplement) including (B) expanded osculum and excurrent canals (measured canal diameters $d 1-d 3$ are indicated by broken lines) and (C, D) contraction of the osculum and endopinacoderm lining the excurrent canals (arrows). Scale bars: $1 \mathrm{~mm}$. 

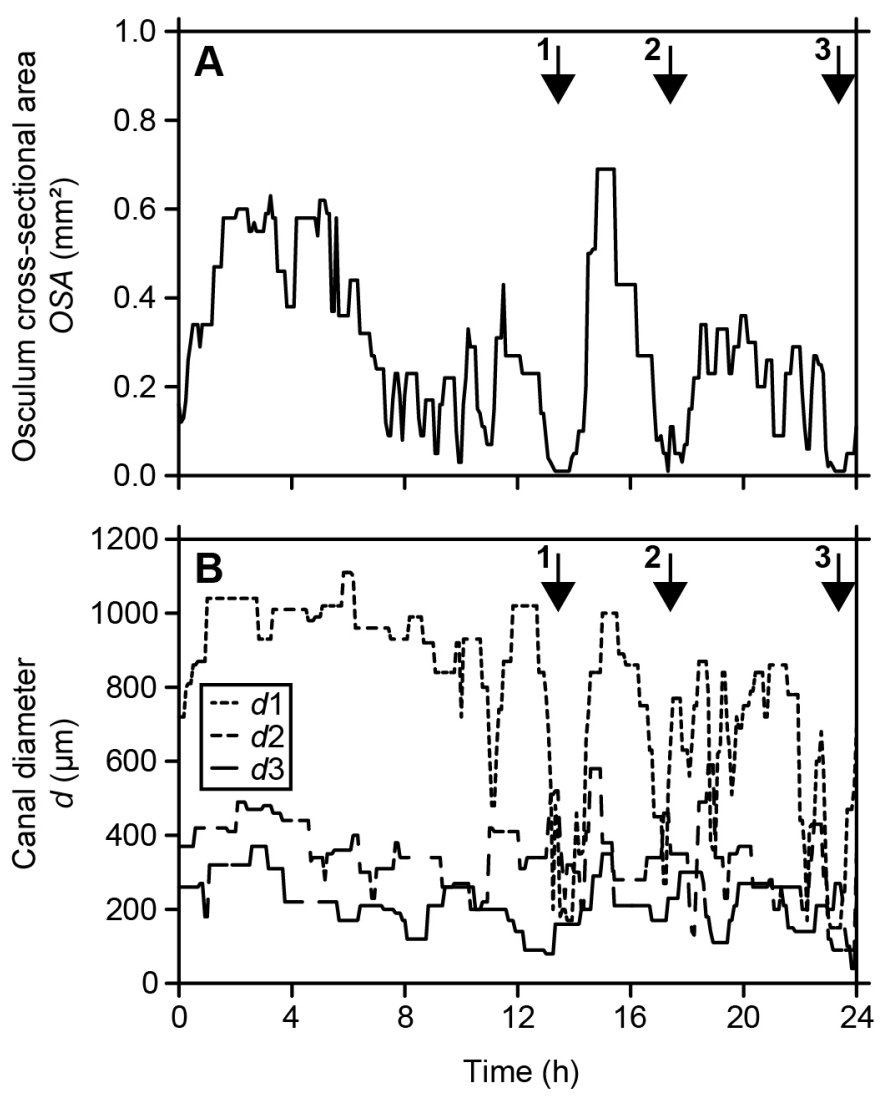

Figure 7. Halichondria panicea. Spontaneous contractions over time of a single-osculum explant (ID \#7; cf. Fig. 6 \& Video 1 in Supplement), expressed by (A) repeated osculum closure (contraction-expansion events 1-3, arrows) and (B) associated constriction of excurrent canals (arrows; cf. d1-d3, Fig. 6B). 


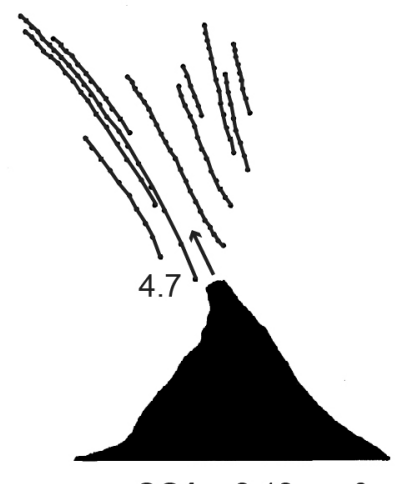

$O S A=0.10 \mathrm{~mm}^{2}$

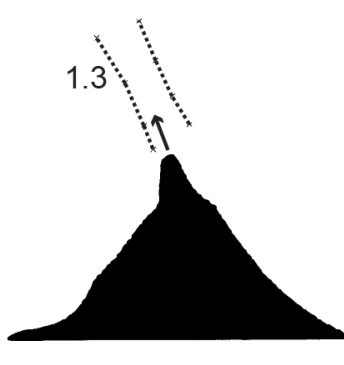

$\mathrm{OS} A=0.05 \mathrm{~mm}^{2}$
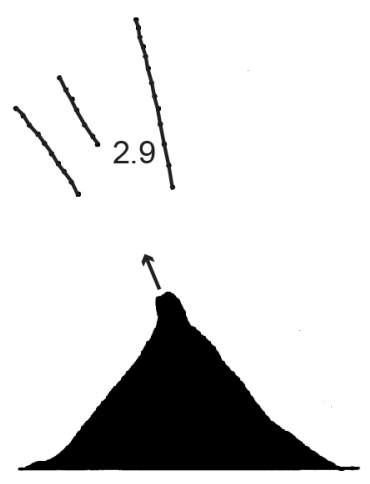

$O S A=0.08 \mathrm{~mm}^{2}$

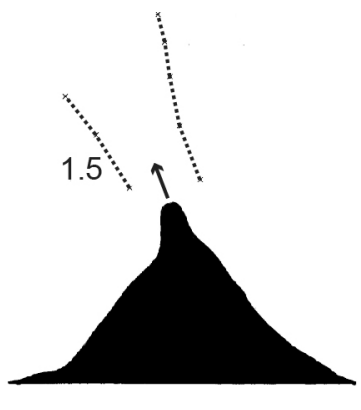

$\mathrm{OSA}=0.04 \mathrm{~mm}^{2}$
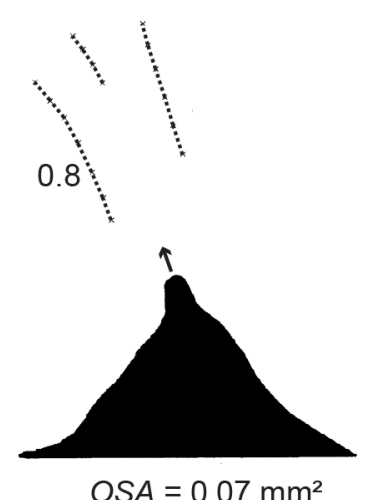

$O S A=0.07 \mathrm{~mm}^{2}$

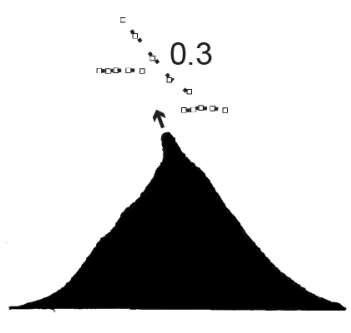

$O S A=0.02 \mathrm{~mm}^{2}$

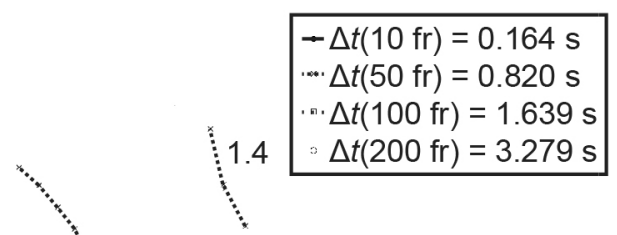

0.1

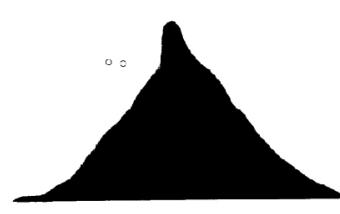

$\mathrm{OSA}=0.00 \mathrm{~mm}^{2}$

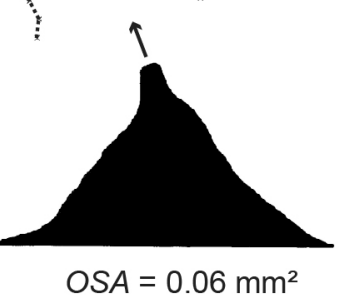

$O S A=0.06 \mathrm{~mm}^{2}$
Figure 8. Halichondria panicea. Flow pattern and speeds of tracer particles accelerated by the (particle-free) exhalant jet of an explant during osculum closure (at $t=0,4,8,15,20,25,30 \mathrm{~min}$; Fig. 9, ID \#1) triggered by addition of GABA (1 mM; at $t=0)$. Ink particles $\left(2 \times 10^{5}\right.$-fold dilution) were traced over 10- $(\bullet), 50-(+), 100-(\square)$, or 200-frame (o) intervals ( $\Delta t$; from 60.61 fps video recordings).

The maximum observed particle speed $\left(U_{\max }, \mathrm{mm} \mathrm{s}^{-1}\right)$ is indicated for each instantaneous cross-sectional area $\left(O S A, \mathrm{~mm}^{2}\right)$. Scale bar: $1 \mathrm{~mm}$. 

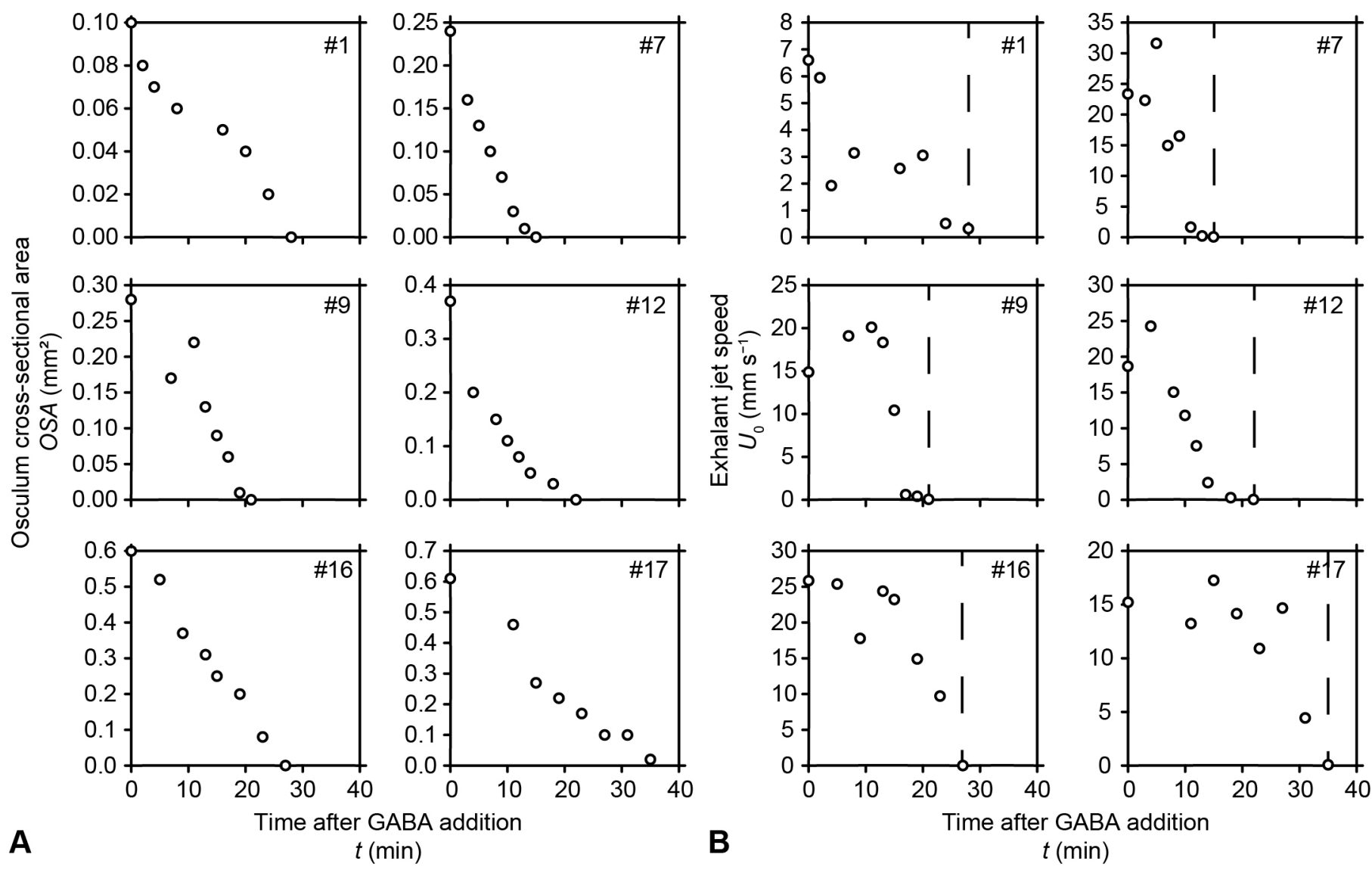
$t$ (min)
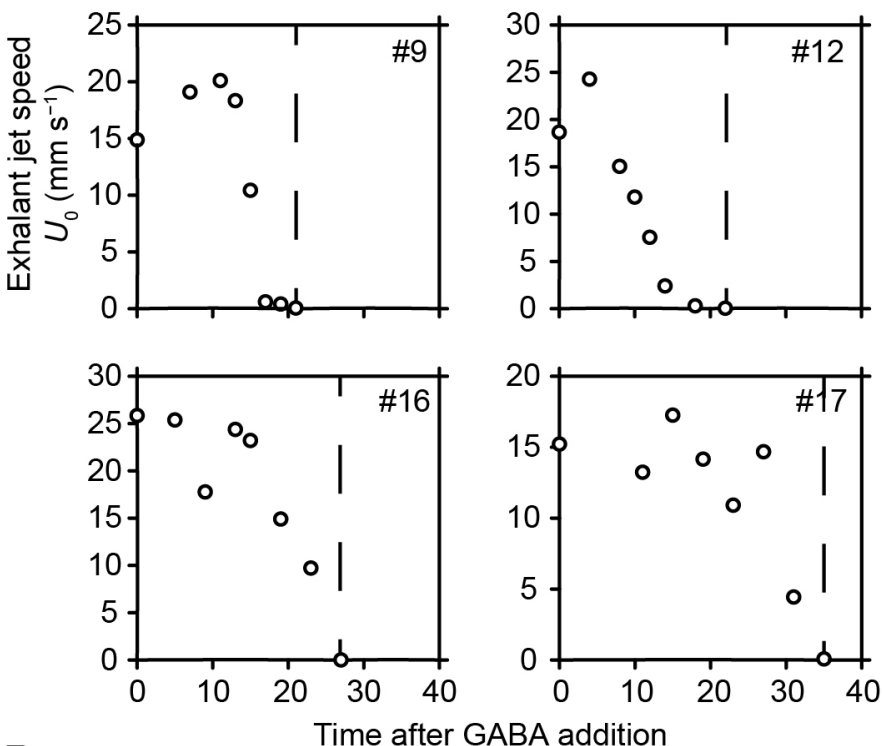

B

$t$ (min)

Figure 9. Halichondria panicea. (A) Osculum cross-sectional area $(O S A)$ and (B) exhalant jet speed $\left(U_{0}\right)$ of selected single-osculum explants (ID\#, Table 1) after addition of the neurotransmitter GABA $(1 \mathrm{mM})$ at $t=0$. The response time $t_{\mathrm{c}}$ for GABA-triggered reductions in the exhalant jet speed $U_{0}$ to zero is indicated by vertical broken lines. 
487

488

489

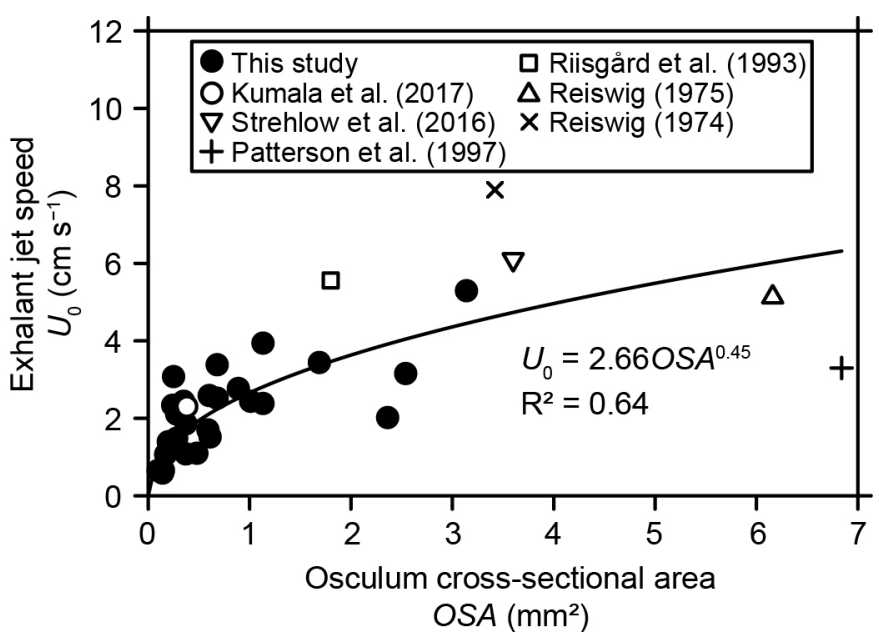

Figure 10. Exhalant jet speed measured in various leucon-type sponge species by different authors (Tables 1 \& 3). 